УДК 352

\title{
ПРОБЛЕМЫ И ПЕРСПЕКТИВЫ УЧАСТИЯ МУНИЦИПАЛЬНЫХ ОБРАЗОВАНИЙ ИРКУТСКОЙ ОБЛАСТИ В РЕАЛИЗАЦИИ РЕГИОНАЛЬНЫХ ПРОЕКТОВ
}

\author{
Прокопьев Никита Алексеевич \\ студент \\ Научный руководитель: Ануфриева Алена Александровна \\ к.э.н., доцент \\ ФГБОУ ВО «Байкальский государственный университет»
}

Аннотация: В статье приводятся основные проблемы органов местного самоуправления при их участии в реализации национальных проектов на территории своих муниципальных образования, анализируется частота и актуальность выявленных проблем, предлагаются возможные пути их решения.

Ключевые слова: национальные проекты, местное самоуправление, органы местного самоуправления, проектное управление, реализация национальных проектов.

\section{PROBLEMS AND PROSPECTS OF PARTICIPATION OF MUNICIPALITIES OF THE IRKUTSK REGION IN THE IMPLEMENTATION OF REGIONAL PROJECTS}

\section{Prokopev Nikita Alekseevich Scientific adviser: Anufrieva Alyona Alexandrovna}

\begin{abstract}
: the article presents the main problems of local self-government bodies with their participation in the implementation of national projects on the territory of their municipalities, analyzes the frequency and relevance of the identified problems, suggests possible ways to solve them.

Keywords: national projects, local self-government, local self-government bodies, project management, implementation of national projects.

Сегодня реализация национальных проектов осуществляется на всех уровнях публичной власти Российской Федерации. И если организационная, методическая, кадровая обеспеченность проектного управления в органах государственной власти за последние годы улучшилась, о чем свидетельствует практика формирования региональных офисов во всех субъектах РФ, успешная
\end{abstract}


разработка и реализация региональных составляющих национальных проектов, то органы местного самоуправления испытывают значительные трудности внедрения проектного управления на своих территориях. На муниципальном уровне наблюдается наибольшее отставание в освоении средств по национальным проектам, отсутствие компетентных кадров и многое другое. При этом население будет оценивать нацпроекты по результативности мероприятий, реализованных на каждой конкретной территории, в каждом конкретном в муниципальном образовании. Это говорит не только о важности активного участия органов местного самоуправления в нацпроектах, но и необходимости совершенствования организации проектной деятельности на местах.

Органы местного самоуправления участвуют в осуществлении мероприятий региональных проектов, направленных на реализацию национальных проектов "Жилье и городская среда", "Образование", "Здравоохранение", "Демография", "Культура", "Экология", "Цифровая экономика", "Малое и среднее предпринимательство и поддержка индивидуальной предпринимательской инициативы", "Производительность труда и поддержка занятости", "Безопасные и качественные автомобильные дороги" и Комплексного плана модернизации и расширения магистральной инфраструктуры на период до 2024 года.

Настоящее исследование посвящено анализу проблем, с которыми сталкиваются муниципальные образования Иркутской области при реализации национальных проектов. Целью исследования является определение проблем организации проектной деятельности в муниципальных образованиях при реализации национальных проектов на своих территориях.

Задачи исследования:

1) изучить формы и способы участия муниципальных образований Иркутской области в реализации национальных проектов;

2) выявить недостатки организации проектной деятельности органов местного самоуправления при реализации национальных проектов на своей территории;

3) определить пути возможного решения имеющихся проблем.

Национальные проекты реализуются на всей территории Российской Федерации в соответствии с указом Президента Российской Федерации от 21 июля 2021 года № 474 «О национальных целях развития Российской Федерации на период до 2030 года». Выделено 3 направления достижения национальных целей («человеческий капитал», «комфортная среда для жизни», 
«экономический рост») в рамках которых реализуется 12 национальных проектов, включающих 67 федеральных проектов. На рисунке 1 представлена схема организации проектной деятельности в Российской Федерации.

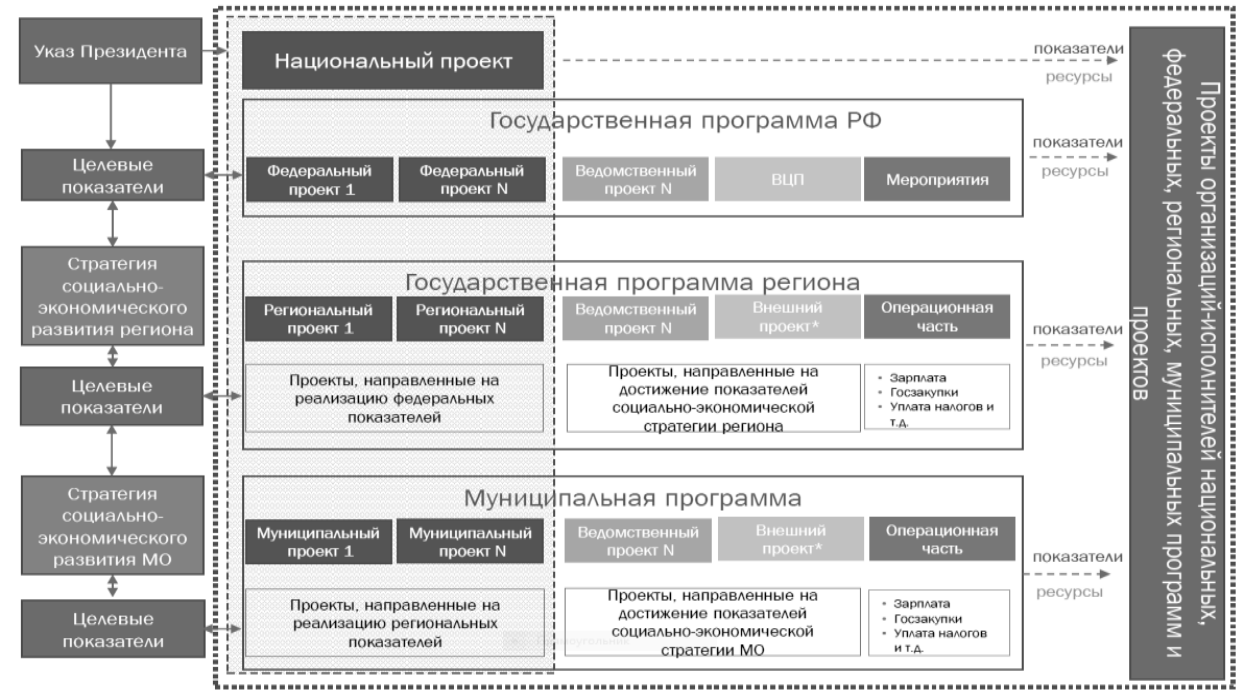

Рис. 1. Схема организации проектной деятельности в Российской Федерации

В Иркутской области в 2020 году реализовывались мероприятия 49 региональных проектов. Общий объем финансирования по мероприятиям региональных проектов в 2020 году составил 27,1 млрд рублей (средства федерального бюджета 16,2 млрд рублей, средств областного бюджета 10,9 млрд рублей), из которых более 40\%, направляется в местные бюджеты 111 муниципальных образований. В 2019 году исполнение региональных проектов Иркутской области составило 87,3\%, в 2020 году - 97\%.

В 2021 году объем субсидий и иных межбюджетных трансфертов муниципальным образованиям Иркутской области составит свыше 11 млрд руб. и будет направлен на реализацию 13 региональных проектов.

Основы ведения проектной деятельности в Иркутской области определены постановлением Правительства Иркутской области от 3 июня 2019 года № 440-пп «Об организации проектной деятельности в Иркутской области». Система проектного управления в Иркутской области включает в себя региональный проектный офис (управление проектной деятельности Губернатора Иркутской области и Правительства Иркутской области) и ведомственные проектные офисы.

На данный момент ведется работа по формированию ведомственных проектных офисов в органах исполнительной власти Иркутской области и формированию муниципальных проектных офисов. В таблице 1 представлены 
основные проблемы осуществления проектного управления в Иркутской области.

Таблица 1

\section{Основные проблемы осуществления проектного управления в Иркутской области}

\begin{tabular}{|c|c|}
\hline $\begin{array}{l}\text { Результаты работ по организации проектной } \\
\text { деятельности, разработке и реализации } \\
\text { региональных проектов в Иркутской области }\end{array}$ & $\begin{array}{l}\text { Проблемы организации проектной } \\
\text { деятельности и реализации региональных } \\
\text { проектов в Иркутской области }\end{array}$ \\
\hline \multicolumn{2}{|c|}{ Организация проектной деятельности } \\
\hline Сформирован региональный проектный офис & $\begin{array}{l}\text { Отсутствует система оценки результативности } \\
\text { и эффективности деятельности ведомственных } \\
\text { и муниципальных проектных офисов. }\end{array}$ \\
\hline \multirow[t]{3}{*}{$\begin{array}{l}\text { Разработаны методические рекомендации по } \\
\text { организации проектной деятельности в } \\
\text { органах местного самоуправления }\end{array}$} & $\begin{array}{l}\text { Недостаточный уровень межведомственного и } \\
\text { межуровневого взаимодействия при } \\
\text { реализации региональных проектов }\end{array}$ \\
\hline & $\begin{array}{l}\text { Недостаточно развитая культура проектного } \\
\text { управления в государственных органах } \\
\text { исполнительной власти и органах местного } \\
\text { самоуправления, а также. }\end{array}$ \\
\hline & $\begin{array}{l}\text { Низкий уровень подготовки кадров в системе } \\
\text { муниципального управления для внедрения и } \\
\text { осуществления проектного управления }\end{array}$ \\
\hline \multicolumn{2}{|c|}{ Реализация региональных проектов } \\
\hline $\begin{array}{l}\text { В реализацию региональных проектов } \\
\text { вовлечена большая часть муниципальных } \\
\text { образований }\end{array}$ & $\begin{array}{l}\text { Несоответствие декомпозированных значений } \\
\text { показателей национальных проектов } \\
\text { предоставляемому объему трансфертов из } \\
\text { федерального бюджета в Иркутскую область. } \\
\text { Некорректно поставленные цели и критерии } \\
\text { исполнения проектов, создание стимулов для } \\
\text { формального достижения целей }\end{array}$ \\
\hline $\begin{array}{l}\text { Увеличение уровня освоения бюджетных } \\
\text { расходов на реализацию региональных } \\
\text { проектов }\end{array}$ & $\begin{array}{l}\text { Недостаточный уровень освоения бюджетных } \\
\text { расходов при реализации проектов в } \\
\text { муниципальных образованиях }\end{array}$ \\
\hline $\begin{array}{l}\text { Несколько муниципальных образований стали } \\
\text { победителями Всероссийского конкурса } \\
\text { лучших проектов создания комфортной } \\
\text { городской среды }\end{array}$ & $\begin{array}{l}\text { Отсутствие финансовых возможностей } \\
\text { участия муниципальных образований в } \\
\text { реализации региональных проектов }\end{array}$ \\
\hline
\end{tabular}

Участие органов местного самоуправления в реализации региональных проектов осуществляется посредством:

- включения в паспорта региональных проектов результатов, достижение которых относится к вопросам местного значения муниципальных образований;

- отражения в паспортах региональных проектов финансового обеспечения достижения результатов региональных проектов, в том числе с указанием средств консолидированных бюджетов субъектов Российской Федерации; 
- включения в паспорта региональных проектов представителей органов местного самоуправления;

- участия органов местного самоуправления в органах управления проектной деятельностью субъектов Российской Федерации.

Участие органов местного самоуправления Иркутской области в реализации региональных проектов осуществляется в форме и в рамках муниципальных проектов муниципальных образований Иркутской области, а также в рамках муниципальных программ. На рисунке 2 отражена степень участия муниципальных образований в государственных программах Иркутской области.

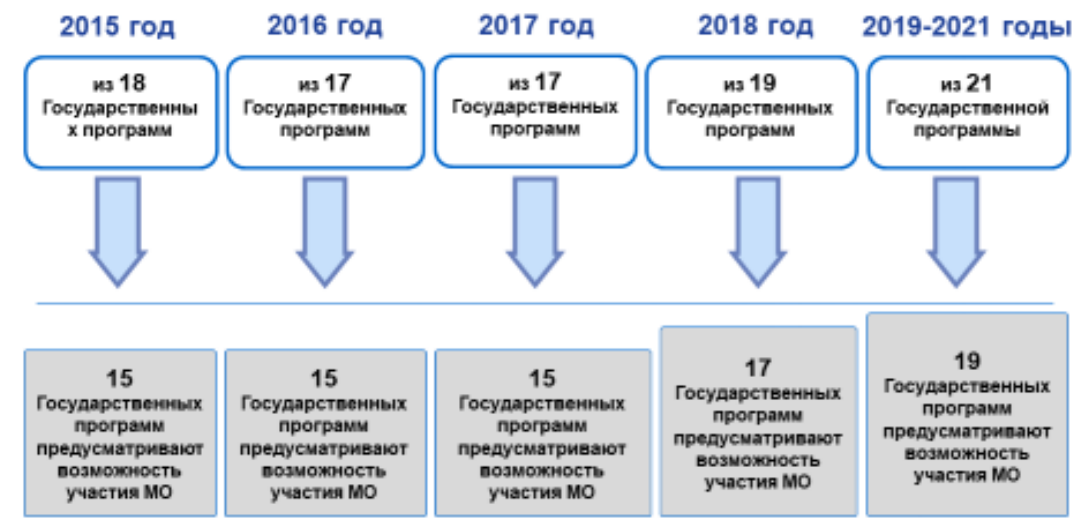

Рис. 2. Участи муниципальных образований в государственных программах Иркутской области

Для содействия реализации национальных проектов на территориях муниципальных образований Иркутской области создаются муниципальные проектные офисы и муниципальные проектные комитеты, их функции и участники представлены на рисунке 3.
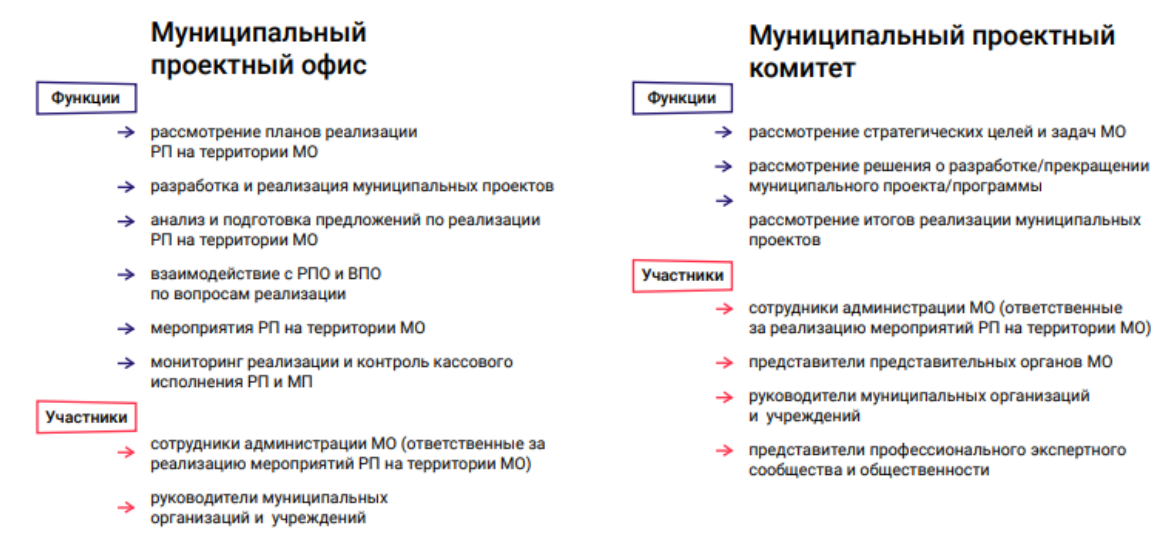

Рис. 3. Функции и участники муниципальных проектных офисов и проектных комитетов 
Для анализа проблем муниципальных образований при реализации национальных проектов были использованы данные, поученные в ходе прохождения автором учебной практики в управлении проектной деятельности Губернатора Иркутской области и Правительства Иркутской области. Сведения были предоставлены исполнительно-распорядительными органами власти муниципальных образований Иркутской области во исполнение запроса Комитета Совета Федерации по федеративному устройству, региональной политике, местному самоуправлению и делам Севера для подготовки к заседанию Президиума Совета законодателей Российской Федерации на тему «Работа над реализацией национальных проектов в субъектах Российской Федерации».

Автором систематизирована информация о проблемах, с которыми сталкиваются органы местного самоуправления при реализации национальных проектов на своей территории, а также разработаны предложения по их решению. В таблице 2 приведены сведения о наличии и количестве существенных для муниципалитетов проблем (анализ проводился по муниципальным образованиям, предоставившим данную информацию):

Таблица 2

Количество проблем, с которыми сталкиваются муниципальные образования при реализации национальных проектов

\begin{tabular}{|l|c|c|c|c|c|c|}
\hline \multirow{2}{*}{$\begin{array}{c}\text { Количество } \\
\text { обозначенных проблем }\end{array}$} & \multicolumn{2}{|c|}{ Городские округа } & \multicolumn{2}{c|}{ Муниципальные районы } & \multicolumn{2}{|c|}{ МО в целом } \\
\hline $\begin{array}{l}\text { Информация не } \\
\text { предоставлена }\end{array}$ & 5 & 50 & 22 & 69 & 27 & 64 \\
\hline 0 & 0 & 0 & 5 & 16 & 5 & 12 \\
\hline $1-2$ & 2 & 20 & 3 & 9 & 5 & 12 \\
\hline 3 и более & 3 & 30 & 2 & 6 & 5 & 12 \\
\hline Итого & 10 & 100 & 32 & 100 & 42 & 100 \\
\hline
\end{tabular}

Большинство муниципальных образований не предоставило информацию, что может свидетельствовать о неучастии муниципальных образований или низкой заинтересованности органов местного самоуправления в реализации национальных проектов. При этом удельный вес муниципальных образований, не предоставивших информацию либо заявивших об отсутствии проблем, выше в муниципальных районах, чем в городских округах. Наиболее подробная информация была предоставлена Ангарским городским округом, который предоставил не только детальный анализ проблем, но и предложения 
по внесению изменений в действующие нормативные правовые акты для решения имеющихся проблем.

Описанные проблемы были разделены на локальные (касающиеся конкретной ситуации в конкретных муниципальных образованиях) и общие (касающиеся большого количества муниципальных образований). Произведена классификация общих проблем, исключены проблемы, о наличии которых сообщило только одно муниципальное образование. В таблице 3 отражена частота упоминания проблем относительно общего числа муниципальных образований, сообщивших о наличии проблем при реализации национальных проектов на их территории.

Таблица 3

Частота упоминания проблем, с которыми сталкиваются муниципальные образования при реализации национальных проектов

\begin{tabular}{|l|l|l|l|}
\hline $\begin{array}{l}\text { № } \\
\text { п.п. }\end{array}$ & Наименование проблемы & $\begin{array}{l}\text { Количество } \\
\text { МО, заявивших } \\
\text { о наличии этой } \\
\text { проблемы }\end{array}$ & $\begin{array}{l}\text { Доля МО, } \\
\text { сообщивших о } \\
\text { наличии каких-либо } \\
\text { проблем, от общего } \\
\text { числа МО \% }\end{array}$ \\
\hline 1 & $\begin{array}{l}\text { Отсутствие показателей, отражающих вклад } \\
\text { конкретных МО в реализацию национальных } \\
\text { проектов }\end{array}$ & 2 & 20 \\
\hline 2 & $\begin{array}{l}\text { Низкий уровень методического и } \\
\text { информационного обеспечения специалистов } \\
\text { МО }\end{array}$ & 3 & 30 \\
\hline 3 & $\begin{array}{l}\text { Недостаточность средств местных бюджетов } \\
\text { для обеспечения необходимой доли } \\
\text { софинансирования }\end{array}$ & 5 & 30 \\
\hline 4 & $\begin{array}{l}\text { Дефицит кадров в сфере проектной } \\
\text { деятельности }\end{array}$ & 20 \\
\hline 5 & $\begin{array}{l}\text { Избыточный контроль правоохранительных } \\
\text { органов }\end{array}$ & 2 & 60 \\
\hline 6 & $\begin{array}{l}\text { Недостаточность собственных средств МО для } \\
\text { составления необходимой проектной } \\
\text { документации и прохождения государственной } \\
\text { экспертизы }\end{array}$ & 6 & 100 \\
\hline 7 & Итого МО, заявивших о наличии проблем & 10 & 2 \\
\hline
\end{tabular}




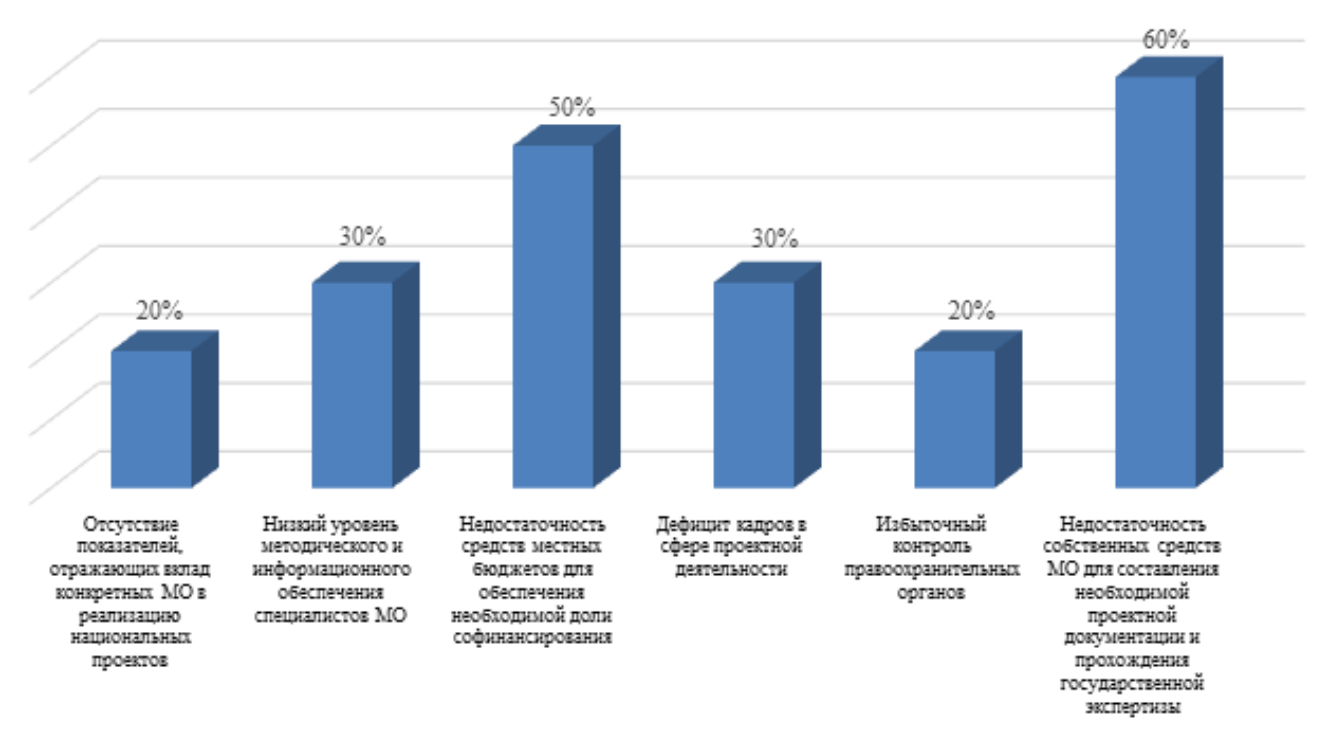

Рис. 4. Частота упоминания проблем, с которыми сталкиваются муниципальные образования при реализации национальных проектов

Основные проблемы при реализации национальных проектов связаны с тем, что у муниципальных образований недостаточно средств для участия в них. Можно выделить 3 основных направления расходов муниципальных средств в рамках национальных проектов: расходы на создание проектной документации (проекты школ, детских садов, физкультурно-оздоровительных комплексов, фельдшерско-акушерских пунктов и т.д.), расходы на прохождение государственной экспертизы проектной документации, расходы, связанные с софинансированием.

Решение проблемы нехватки средств на проектирование и прохождение государственной экспертизы муниципальные образования видят в предоставлении областной субсидии на эти цели, что позволит возмещать затраты за счет средств областного бюджета. Также предлагается использовать типовые проекты, что позволит сократить расходы на проектирование.

Учитывая, что в большинстве муниципалитетов сохраняется несоответствие объема полномочий органов местного самоуправления имеющимся в их распоряжении материально-финансовым ресурсам и в полном объеме финансируются только первоочередные статьи расходов, главной проблемой органов местного самоуправления по реализации муниципальных проектов является дефицит местных бюджетов, ограниченные возможности на софинансирование строительства объектов инженерной и социальной инфраструктуры. В связи с чем, предлагается пересмотреть уровень софинансирования муниципалитетов при реализации мероприятий 
региональных (муниципальных) проектов, предусматривающих привлечение средств федерального и областного бюджетов.

Вторая группа проблем связана с недостаточным информационным и методическим сопровождением реализации национальных проектов. Проекты не включены в документы стратегического планирования, хотя фактически ими являются (упоминания национальных проектов нет в федеральном законе от 28 июня 2014 года №172-Ф3 «О стратегическом планировании в Российской Федерации»). Отсутствует взаимосвязь между стратегиями развития муниципальных образований и нацпроектами, наблюдается рассогласованность по целям, приоритетам, задачам, мероприятиям, показателям, финансовым и иным ресурсам, срокам реализации.

Необходимо добавить показатели участия муниципальных образований в паспорта региональных проектов, чтобы было возможно оценить вклад конкретных муниципальных образований, а также ставить задачи не только по отдельным органам исполнительной власти, но и по территориям.

Еще одной важной проблемой является дефицит кадров в сфере проектной деятельности в муниципальных образованиях, низкий уровень подготовки имеющихся кадров. Эту проблему возможно решить путем проведения курсов повышения квалификации для муниципальных служащих, участвующих в реализации национальных проектов.

Таким образом, основными проблемами участия муниципальных образований в Иркутской области являются низкая бюджетная обеспеченность, что выражается в нехватке собственных средств муниципальных образований на составление проектно-сметной документации и прохождении государственной экспертизы, а также низкий уровень кадрового и информационного обеспечения.

\section{Список литературы}

1. Указ Президента Российской Федерации "О целях развития Российской Федерации на период до 2030 года" от 21.07.2020 № 474 // Российская газета.

2. Постановление Правительства Иркутской области "Об организации проектной деятельности в Иркутской области" от 03.06.2019 № 440-пп // Областная газета

3. Национальные проекты // Иркутская область. Официальный портал URL: https://irkobl.ru/region/priority/ (дата обращения: 10.04.2021). 
4. Доклад о лучших муниципальных практиках участия в реализации региональных проектов, обеспечивающих достижение целей, показателей национальных проектов и результатов их реализации // Министерство экономического развития Российской Федерации URL: https://www.economy.gov.ru/material/news/minekonomrazvitiya_ rossii_vybralo_luchshie_praktiki_uchastiya_municipalitetov_v_realizacii_nacionalny h_proektov.html (дата обращения: 10.04.2021).

5. Голованов, В. И. Роль муниципальных образований в реализации национальных проектов / В. И. Голованов // Муниципальная академия. - 2019. — № 3. - C. 101-107.

(C) Н.А. Прокопьев, 2021 